This is an electronic reprint of the original article. This reprint may differ from the original in pagination and typographic detail.

\author{
Author(s): Mäkelä, Tiina; Pnevmatikos, D.; Immonen, Hanna; Fachantidis, N.; Kankaanranta, \\ Marja; Christodoulou, P.
}

Title: $\quad$ Considering Various Stakeholders' Views in the Design of a Hybrid Stem Learning Environment : Perceptions From Finland and Greece

Year: $\quad 2017$

Version:

Please cite the original version:

Mäkelä, T., Pnevmatikos, D., Immonen, H., Fachantidis, N., Kankaanranta, M., \& Christodoulou, P. (2017). Considering Various Stakeholders' Views in the Design of a Hybrid Stem Learning Environment : Perceptions From Finland and Greece. In L. G. Chova, A. L. Martínez, \& I. C. Torres (Eds.), EDULEARN17 Proceedings. 9th International Conference on Education and New Learning Technologies (pp. 55175526). IATED Academy. EDULEARN Proceedings. https://doi.org/10.21125/edulearn.2017.2257

All material supplied via JYX is protected by copyright and other intellectual property rights, and duplication or sale of all or part of any of the repository collections is not permitted, except that material may be duplicated by you for your research use or educational purposes in electronic or print form. You must obtain permission for any other use. Electronic or print copies may not be offered, whether for sale or otherwise to anyone who is not an authorised user. 


\title{
CONSIDERING VARIOUS STAKEHOLDERS' VIEWS IN THE DESIGN OF A HYBRID STEM LEARNING ENVIRONMENT - PERCEPTIONS FROM FINLAND AND GREECE
}

\author{
Tiina Mäkelä1, Dimitris Pnevmatikos², Hanna Immonen³, Nikolaos Fachantidis ${ }^{4}$, \\ Marja Kankaanranta ${ }^{5}$, Panagiota Christodoulou ${ }^{6}$ \\ ${ }_{1,5}$ University of Jyväskylä, Finnish Institute for Educational Research and Faculty of \\ Information Technology \\ ${ }^{3}$ University of Jyväskylä, Finnish Institute for Educational Research \\ ${ }^{2,6}$ University of Western Macedonia, School of Education \\ ${ }^{4}$ University of Macedonia, Department of Social and Educational Policy
}

\begin{abstract}
Raising young people's interest in studies and careers related to science, technology, engineering, and mathematics (i.e., STEM) is an important societal concern both at European and global level. We argue that the creation of attractive and engaging STEM learning environments necessitates involvement of learners, educators, parents, and STEM professionals in their design. In this paper, we will present a study in which primary, lower and upper secondary school students, teachers, school directors, parents, and STEM professionals in Finland $(n=27)$ and Greece $(n=24)$ were invited in the participatory co-design of a hybrid (virtual, physical, formal, and informal) STEM learning environment. The aim of this paper is to present, first, a method employed for the participatory co-design, and, second, display the results from Finland and Greece regarding participants' shared wishes on teaching, learning, assessment, and motivation both in general and in relation to STEM subjects. In addition to recorded focus group discussions with these stakeholder groups and researchers, data were gathered by means of an online survey with open-ended questions which participants filled out during the co-design sessions. Data were analysed based on grounded theory approach and qualitative coding techniques. Amongst the most commonly shared wishes between different stakeholders in both countries raised during the sessions were the importance of connectedness of studies with students' life as well as the use of diverse teaching methods such as collaborative and ICT-enhanced learning. The results of this study are discussed towards to the creation of a pedagogical framework and design principles guiding the development of a hybrid learning environment consisting of components such as a social web platform, e-portfolio, robots, serious games, entrepreneurial tools, and digital radio connecting various stakeholders with an aim to increase youngsters' interest in STEM studies and careers. The results will also contribute to the understanding of how to raise interest in STEM in general. The study is a part of a broader European research project funded by the European Union's Horizon 2020 research and innovation program with partners in Belarus, Finland, Germany, Greece, and Spain.
\end{abstract}

Keywords: STEM, learning environment, design principles, participatory design.

\section{INTRODUCTION}

Raising young people's interest in studies and careers related to science, technology, engineering, and mathematics (i.e., STEM) is an important societal concern both at European and global $[1,2]$ level. Previous studies $[2,3,4,5,6]$ indicate that many young people perceive science teaching as complex, boring, overly theoretical or impractical memorization with no perceived utility in students' life. Also, mathematics is often considered as a difficult subject. Difficulties in mathematics may decrease the interest and cause negative attitudes and anxiousness towards studying it. Further, student attitudes towards specific subjects are found to be strong determinants of students' choice in pursuing future careers. Negative attitudes towards science subjects and mathematics are, therefore, likely to decrease students' motivation to pursue careers in STEM.

Finland and Greece share the concern related to the decrease in both competences and interest in 
science and mathematics amongst their youngsters. In the OECD's Programme for International Student Assessment (PISA) studies conducted in 2015 [7], the performance of 15-year-old Greek students in science and mathematics was clearly below the OECD averages. Further, the science performance of Greek students participating in these assessments has decreased strongly in recent years. While 15-year-old students in Finland continue performing in these comparisons above the OECD averages and clearly higher than Greek students [see also 8], there has also been a clear decrease in the performance in Finland as compared to earlier assessments.

The decreasing interest and performance levels of European youth in science and mathematics appear particularly worrying for EU economy requiring innovative and creative STEM solutions to keep up with the high global economic competition [1]. We argue that, if we are to increase young people's interests in STEM studies, we have to involve them in the design of engaging and attractive STEM environments. Previous studies [9, 4] suggest, that involving students in the learning environment design may augment the desirability and adequacy of these environments for them. Co-designing LE with students is also in line with contemporary student-centred pedagogies and learners' active role as designers of their own learning [9, 10]. Further, it is of vital importance to understand other stakeholders' such as educators', parents', and STEM professionals' views in their design [11, 12]. Only in this way can we design learning environments, which consider various perspectives in a balanced manner.

In this paper, we will present a study in which primary, lower and upper secondary school students, teachers, school directors, parents, and STEM professionals in Finland and Greece were invited in the participatory co-design of a hybrid (virtual, physical, formal, and informal) STEM learning environment. The aim of this paper is to present, first, a method employed for the participatory co-design, and, second, display the results from Finland and Greece regarding participants' shared wishes on teaching, learning, assessment, and motivation both in general and in relation to STEM subjects.

The study is a part of a broader European research project denominated as STIMEY (Science, Technology, Innovation, Mathematics, Education for the Young) funded by the European Union's Horizon 2020 research and innovation program with partners in Belarus, Finland, Germany, Greece, and Spain. The project researches and develops a hybrid educational environment with multi-level components aiming to make STEM education more attractive to young people aged 10 to 18 . This environment will consist of components such as a social web platform, e-portfolio, robots, serious games, entrepreneurial tools, and digital radio and will connect various stakeholders in shared efforts to engage and increase both female and male students' interest in STEM education, innovations, and careers from a young age. The results of the sub-study presented in this paper are discussed towards the creation of a pedagogical framework and design principles guiding the development of this hybrid learning environment. The results will also contribute to the understanding of how to raise interest in STEM in general.

\section{METHODOLOGY}

\subsection{Participants}

Participants representing the main stakeholder groups relevant to this project, i.e., from 10 to 18 -year old primary, lower and upper secondary school students, school directors, teachers, parents and professionals working in STEM careers, were invited to co-design sessions. It was assured that there was a gender balance in volunteering participants. Table 1 displays the number of participants for each stakeholder group.

Table 1. Participants

\begin{tabular}{lccc}
\multicolumn{1}{c}{ Stakeholder group } & Finland $(\mathbf{n})$ & Greece $(\mathbf{n})$ & Total $(\mathbf{n})$ \\
\hline Primary school students & 4 & 2 & 6 \\
\hline Lower secondary school students & 6 & 2 & 8 \\
\hline Upper secondary school students & 2 & 2 & 4 \\
\hline Teachers & 3 & 6 & 9
\end{tabular}




\begin{tabular}{lccc} 
Directors & 3 & 3 & 6 \\
\hline Parents & 5 & 6 & 11 \\
\hline STEM professionals (business and research) & 4 & 3 & 7 \\
\hline Total & 27 & 24 & 51
\end{tabular}

Females, $n=25$ (Finland, $n=14$, Greece, $n=11$ ), Males, $n=26$ (Finland, $n=13$, Greece, $n=13$ )

\subsection{Materials}

The study employed participatory design approach [9,12] and focus group techniques [13]. Materials for the focus group sessions involving various stakeholders in the learning environment co-design were developed in collaboration with the partners participating in the STIMEY project, first in English, and then translated into local languages. Focus group discussions collected participant' wishes related to the main topics covered in the STIMEY project: Teaching and learning, STEM subjects, crosscurricular skills, social media, games and gamification, digital platform, radio, social robots, gender, and safety issues. These topics were presented for the participants in slides entailing inspirational images of each topic. Participants' wishes related to various topics were collected by using an online form with open-ended questions. Focus groups discussions were also recorded. Materials were designed based on the grounded theory approach [14]. Instead of referring to specific theories on learning and motivation and pre-defining these concepts for participants, we were interested in their ideas related to these topics. This paper concentrates on the analysis of the responses of the two following main topics and their subsections: wishes on (1) teaching and learning (1.1. teaching, 1.2. learning, 1.3. assessment, 1.4. motivation) and on (2) STEM subjects (2.1. teaching, 2.2. learning, 2.3. motivation).

\subsection{Procedure}

Main focus groups' co-design sessions were organized in both countries at a primary school, lower secondary school, and upper secondary school during the school year 2016-17. In Finland, some participants who could not be present during the main sessions provided their contributions in separate, additional sessions. Participants' written consents, and in the case of minors, also their parents' consents, were asked in advance. After a short description of the STIMEY project, researchers presented the topics to be discussed one by one using the presentation slides. Sessions lasted from 90 to 120 minutes as a whole leaving approximately from 5 to 10 minutes' time to discuss and write down the wishes related to each topic. While open conversation enabled collaborative idea elicitation between stakeholder groups, writing wishes down enabled expressing oneself without feeling constrained to voice their views in front of the others [cf. 13]. It also gave less extrovert participants chances to participate. Researchers were careful so as not to influence participants' ideas. In the case there was a need to clarify some concepts or give some examples, participants were reminded that there were no right or wrong responses. Participants were, however, encouraged to think and express their wishes as representatives of their stakeholder group instead of thinking only personal preferences.

\subsection{Data analysis}

The data analysis was initiated following the grounded theory approach [14]. First, the written data collected via online form was coded using open coding techniques in which data was broken into meaningful conceptual components. Experts in Finland and in Greece did this independently. During the next step, researchers shared their initial codes based on the data from these two countries. They discussed how each concept could be related to a larger group of concepts or themes. Example responses were provided to each conceptual component. Researchers compared the components identified in each country in order to seek similarities and differences between them. Finally, the codes created in both countries were combined into wider thematic groups so as to create the final list of codes. After this, the second round of analysis was conducted based on shared understanding of the thematic groups. While the open coding was made with no predetermined theoretical assumptions, during the final phase of the coding process, knowledge of existing learning theories and models were used to support grouping the conceptual components into thematic groups and naming them.

During the coding process, we noticed that the themes discussed in sections (1) Teaching and 
learning and (2) STEM subjects and their subsections (see 2.2. Materials) were highly overlapping. For this reason, instead of keeping separate code list for each section, in the final phase of the analysis, we created a unified code list for all sections. This helped us also to see, for example, how participants referred to motivation or assessment when expressing their wishes on teaching and learning in general or in relation to STEM, or vice versa.

\section{RESULTS}

The results presented in this paper focus on the identification of the main wishes that participants brought out. In addition to the descriptive data of the most commonly shared wishes by all stakeholders, some differences in responses between Finnish and Greek participants are presented.

Participants in both countries frequently referred to learning as an active knowledge construction. Under this theme, we grouped wishes related to the importance of considering learner's active agency, active learning, and learning by constructing or creating knowledge. It also entailed comments from Greek participants criticizing teacher-centred teaching or memorization. For example, a Greek female lower secondary school director mentioned that "teaching should not be frontal and teacher-centred" and a female lower secondary school student commented that "[...] studying STEM should not take place through the memorization of tricky texts [...]". Similar importance was also given to the theme labelled as participation and involvement gathering proposals related to the participatory, interactive, and conversational teaching-learning interaction. In Finland, some participants also referred to the dialectic forms of assessment and co-design of learning with students. For example, a female lower secondary school director was in favour of "self-evaluation and evaluation conversations with the teacher". Many participants both in Finland and Greece also referred to collaborative methods, that is, teamwork, group work, cooperation, etc. A Greek female lower secondary school student wished, for instance, that "[...] STEM could be studied in collaboration with other students".

Amongst the most frequently commented aspects were also wishes related to personalized learning referring, for instance, to the importance of considering learner's personal competence level, differences in knowledge, skills, rhythm, and ways of learning. In addition to competence level, participants gave importance to considering personal preferences and interests, and to provide more freedom of choice. Personalized learning and assessment were slightly more commonly wished by the Finnish participants, which also draw attention to both providing support when facing challenges and considering needs of more advanced students. In Finland, a father of a primary school student stated that "every pupil's level should be considered and teaching should be challenging enough and provided in a form that is the most understandable for each individual", and a female lower secondary school student hoped that teaching "would focus more on children's individual strengths and wishes". Further, self-regulated learning (i.e., independent, autonomous, self-directed learning) and reflective learning (i.e., reflection, deep thinking, critical thinking) were brought out as important concerns in both countries but slightly more frequently in Finland than in Greece.

In both countries, participants were also frequently referring to the importance of teacher competences. Teachers were expected, for example, to facilitate effective learning, teaching, and assessment (Greece) and use research know-how in teaching (Finland). In both countries, but more in Greece than in Finland, teachers were also expected to know how to motivate students using attractive, pleasant, and inspiring teaching, which catches students' attention. This finding is supported by the wish of a Greek male upper secondary school director who mentioned that "learning should be pleasant [...] and always getting students' attention".

The importance of connectedness of studies with students' both present and future life was amongst the most frequent comments in both countries. Many participants highlighted the relevance of connecting studies with the outside of school experiences or informal learning. For instance, a mother of a Greek lower secondary school student suggested that "teaching should be carried out [...] so that it could be applied in a practical way in everyday life". Participants also hoped that learning could be perceived as useful for students' future life and careers. Such a wish was provided by a Greek male upper secondary school student who stated that "learning should have as a result that I could work on the field I chose to". A mother of a Finnish upper secondary school student commented: "Motivation would be enhanced by creating connections with labour market and giving students opportunities to familiarize (virtually or physically) with different workplaces and tasks." Also, there was a hope that assessment would be more connected with applying knowledge in practical situations. In relation to STEM subjects, in particular, participants wished that teaching were both connected with the present scientific achievements and discoveries and that it provided tools for students so as to improve STEM development. As wished by a Greek female STEM professional: "Studying STEM could be employed 
for the development of new ideas and technologies". Highly related to the connectedness of studies with the present and future life, also learning outside the school (i.e., field trips, visits to workplaces) was suggested by many participants.

Further, the importance of learning through experiences, i.e., learning based on every day or real-life examples, experiential learning, and learning by doing, was made evident in focus group co-design sessions organized in both countries. In relation to STEM studies, in specific, participants frequently wished that there were learning through experiments and inquiry, entailing laboratory experiments, scientific inquiry in learning, discovery learning, and problem-based learning. For instance, both a Finnish male primary school teacher and a Greek female lower secondary school student wrote about the importance of "experiments and observations". A Finnish female primary school student hoped that they could "investigate things by themselves", a wish also supported by a Finnish male primary school director favouring "inquiry-based learning and experiments". Particularly Greek participants seemed to highlight the importance of having science labs at schools. For instance, a Greek female lower secondary school teacher stated that "physics and chemistry should be carried out in a properly equipped laboratory".

Some participants also referred to project-based learning, i.e., learning through cross-curricular or transversal projects, phenomenon-based learning or linking different subjects. A Finnish female primary school teacher wished that motivation towards STEM was increased by "child-centred wider projects" and Finnish female upper secondary school director envisioned "a learning environment which reinforces the integration of STEM subjects with one another and with other subjects, that is, holistic knowledge construction."

Wishes related to ICT-enhanced learning were abundant in all focus group sessions. This theme included comments related to use of technology, such as technical aids, mobile technology, virtual glasses, electronic measuring systems, platforms, robots and digital assessment tools. For instance, a Finnish male lower secondary school student proposed that "there would be novel technology such as holograms". Further, a theme labelled as use of games and gamification was created based on frequent comments particularly from Finland related to learning games and game-like elements including also non-digital components such as the use of play, stories, and narrative. A Finnish female lower secondary school student wanted "more technology and learning games". A male STEM professional participating in the focus group sessions in Finland stated: "The focus should be more on laboratory and hands-on work, playful learning and the use of ICT..." Further, comments from both Greek and Finnish participants referring to various both digital and non-digital forms of presenting information including visuals, multimedia, audio, simulations, and animations, were gathered under the thematic group labelled as the use of multiple representations.

The importance of versatility in teaching, learning, and assessment for participants was evident throughout the data. Participants frequently, in Finland fairly more than in Greece, referred to the importance of versatile and varying methods, tools and learning environments. They also asked for assessment based on various criteria such as knowledge, skills, interests, attitudes, and behaviour and, instead of only the final exam, on different activities completed during the learning process. Versatility was also frequently mentioned in relation to aspects that would increase motivation in learning in general and in learning STEM subjects. For instance, a Finnish male upper secondary school teacher wished that motivation were "increased by varying approaches in teaching situation" and two Finnish female lower secondary school students hoped for "varying ways of teaching".

Another theme frequently commented in both countries but somewhat more in Finland, was the importance of novelty. Under this theme, we grouped suggestions related to the novel and innovative methods and tools instead of conventional teaching and materials such as books. In Finland, some participants referred to the importance of physical activities in learning, or "more physical exercise" as asked by a female primary school student. In relation to novel assessment, quite a few participants requested either fewer exams or no exams or assessment at all. In both countries, some participants were also opposed to numeric grades. It is worth mention, however, that although wishes related to novelty were more frequent, we also identified some positive comments related to conventionality. Participants commented, for example, that the use of books, pencils, and paper should not be abandoned. Most of these comments came from Finnish participants. For example, in Finland, both a female and male upper secondary school student wished that "numeric grading were not abandoned".

The importance of joy of learning was also evident throughout the responses. Participants referred to the importance of enjoyment, learner satisfaction, and having fun. Some participants also commented that assessment should not cause negative consequences but should promote a positive climate and 
encourage students. In Greece, in particular, some participants expressed their worries on long school days, homework, and extracurricular work at the expense of students' free time thus affecting their joy of learning. A Greek male primary school student suggested that "learning should take place at school and students should not have homework at home" and a father of an upper secondary school student stated that "learning should [...] not reduce students free time". There were also comments related to the importance of positive social climate for learning fostered by good peer and teacher-student relations. A Greek female upper secondary student stated that "[...] the teacher should be friend with his students". Further, relatively many participants, especially from Greece, referred to the importance of justice and equity or equal treatment of all students, no discrimination, and fair assessment. Such an example was provided by a Greek male lower secondary school teacher who mentioned that "assessment should be fair [...] and be carried out with attention".

Finally, in relation to motivation, we noticed that motivation was a frequent theme commented not only in subsections directed to this topic but throughout all sections. We noticed that we could classify many participant comments under intrinsic motivation, e.g., the inner need to learn, personal interests, desires, needs, and competencies. These wishes were somewhat more frequent in Greece than in Finland. For example, a father of a Greek lower secondary school student expressed that "students should have an inner desire for learning". In relation to extrinsic motivation, participants referred to the importance of positive and rewarding feedback, encouragement and rewards, on one hand. On the other hand, they desired inspiring, comfortable and good learning environments, equipment, tools, and materials. For instance, a Finnish male lower secondary school student argued that "providing armchairs for students" and a Greek male upper secondary school student that "providing better books" would increase students' motivation.

\section{DISCUSSION}

Wishes related to teaching, learning, motivation, and assessment both in general and in relation to STEM studies, identified in this analysis based on various stakeholders' views in Finland and Greece, are expected to contribute to the creation of a pedagogical framework and design principles for attractive and engaging STEM learning environments. These results are also expected to contribute to the understanding of how to raise interest in STEM in general. The grounded theory approach [14] of this study led us to seek various stakeholders' views without being guided by a specific previous theoretical model. When analysing the results, we could, however, identify how participants' wishes were related particularly to student-centred learning approaches connected to constructivist, social constructivist, and cognitive learning theories, as well as pedagogical models and design principles related to these theories and models.

In line with student-centred learning principles [e.g., 15], participants in both countries wished that learning were active, participatory, and collaborative knowledge construction. The results are also in harmony with the pedagogical learning principles named as "facilitating knowledge building rather than providing a discussion forum" and "providing tools for community building" applied in the design of web-based collaborative learning environments following progressive inquiry model [16, 17, 18]. Notions related to personalized, self-regulated, and reflective learning, in turn, are in line with the student-centred learning principles considering learners' prior knowledge and personal needs, giving responsibility, autonomy, and possibilities for choice, as well as encouraging reflexive approach, deep learning, and understanding [15].

Wishes for fostering connectedness of studies and learning outside the school resemble design principles named as "fostering authenticity" and "interlinking working and learning" developed based on both theoretical (cognitive constructivist, sociocultural and situational learning theories) and empirical (interviews of university students and faculty members) considerations for learning between school and workplace [19]. They are also linked with strategies for student-centred learning such as fieldwork and developing transferable skills, which go beyond the course requirements and may be beneficial for the future employment [15]. Likewise, the progressive inquiry model considers the need to connect learning with real-world problems meaningful to learners $[17,18]$. We argue that connections with students' future careers should be initiated already during the primary school years when learners are yet free to dream about different career options. Based on the results of this study, it also seems important to consider how to increase the presence of STEM professionals at learning environments both by their visits to schools and by students visiting workplaces, either virtually or physically.

Wishes related to learning through experiences, experiments, and inquiry could be seen as connected 
to student-centred approaches such as experiential learning, inquiry-based learning, and problembased learning $[15,17,18]$. The results of this study also indicate that following the pedagogical principles of the project-based learning ( $\mathrm{PBL}$ or $\mathrm{PjBL}$ ) may support the design of attractive and engaging STEM learning environment and increase interest in STEM. This constructivist form of instruction, which has some similarities with the problem-based learning and experiential learning, is characterized by elements such as students' autonomy and active involvement, collaboration, context dependency, and reflection within real-world practices [20,2], all aspects desired by the stakeholders participating in this study. The use of PBL also seems recommendable in the light of the research literature. For instance, in the literature review of PBL [20], some possible positive results identified were high levels of student engagement due to the cognitive challenge and affective factors, improved self-regulated learning, intrinsic motivation, creative and deep thinking, and science content understanding. In a study on multidisciplinary STEM university course following PBL [2], in turn, this approach was found to increase the effectiveness of studies, generate meaningful learning, influence in future career pursuit, and make students feel that STEM was important to society, health and life.

The results also indicated that integrating both technology studies and learning with technology into science and mathematics may be an effective way to raise young people's interests towards STEM [see also 2, 3]. Interestingly, the use of modern digital technology is also viewed as one facilitating factor in implementing PBL [20]. Further, the progressive inquiry model may be employed in computersupported collaborative learning $[17,18]$ thus combining the elements of inquiry, use of ICT, and collaboration, all wished by the participants of this study.

While the main focus of this analysis was on the identification of shared wishes expressed by both the Finnish and Greek participants, we also identified some possible country-based differences in stakeholders' perceptions. For instance, Finnish participants seemed to pay more attention than Greeks on personalized and self-regulated learning, use of games and gamification, versatility, and novelty. The prevalence of these themes in the Finnish data may be explained by their relatedness with the contemporary discourse around the recently updated Finnish national core curriculum [21] entailing these topics. For example, novel methods such as learning by moving and cross-curricular projects are included in the updated curriculum. It is possible that Greek participants did not frequently discuss these issues due to the less awareness of these topics created by the Greek contemporary educational discourse. On the other hand, the Finnish discourse of novel ways and tools for working also seems to awaken comments reminding that this should not be done by completely abandoning the conventional methods and tools [see also 22].

Greek participants, in turn, seemed to pay more attention to the importance of teacher competencies in teaching, motivating, and assessing students. They also seemed to perceive a stronger need for the science labs and more frequently stated wishes regarding intrinsic motivation factors. Further, they were more concerned for the need for free time than Finnish participants. It is possible that these concerns were expressed more in Greek context as the participants perceived the stronger need to improve these factors in comparison to their Finnish counterparts. For example, the need for better science labs or classrooms with the specific laboratory equipment has been identified in Greece [23].

In a previous study on science learning in Finland and Greece [8], attention was paid on the higher average science performance of Finnish students and the lower level of core competences of Greek students. Also, the science learning activities including experiments and explanations as well as use of specific ICT applications were seen to be integrated in Finland from the level of primary education while in Greece they were not implemented or implemented only at the level of secondary education (regarding the use of specific ICT applications). Further, the level of autonomy and responsibility of Finnish teachers was found to be greater than in Greece. The differences between the educational performance and also teacher competence between these two countries may also partly explain the differences in some wishes.

For example, personalized and self-regulated learning wished particularly in Finland requires highly competent teachers who gradually guide learners towards more self-regulated ways of learning. Also, the success of constructivist, discovery, problem-based, experiential, and inquiry-based teaching is found to be connected with the teacher's' competence to effectively scaffold students' learning and provide guidance and support, and with the balance between didactic instruction with in-depth inquiry methods [20]. It is important that teachers identify particularly the need for a novice or intermediate learners for the stronger instructional guidance [24]. It seems that all teachers, but maybe, even more, teachers in Greece than in Finland, need support in their demanding tasks of guiding learners towards more personalized and self-regulated ways of learning. In line with these ideas, pedagogical learning principles such as scaffolding progressive inquiry, supporting the active role of tutors, and providing 
tools for structuring and coordinating activity, applied in the design of web-based collaborative learning environments [16], seem beneficial.

The results of PISA 2015 may also support interpreting the motives behind more frequent wishes of Greek participants for the intrinsic motivation and free time in comparison to Finnish participants. In this assessment [7], Finnish students' achievement motivation, i.e., the desire to be one of the best students in the class was found to be one of the lowest among the participant countries indicating that Finnish students are not so much driven by the external pressure for succeeding. Also, the average level of student's life satisfaction was one of the highest. On the contrary, the average level of Greek student's life satisfaction was one of the lowest. Further, the percentage of Greek students who reported that they exercise or practice sports before or after school was one of the lowest among PISA-participating countries.

According to Self-Determination Theory [25, 26], learning environments, which provide learners opportunities to fulfil their basic psychological needs, facilitate the development of intrinsic motivation [see also 4]. Is it possible that Greek educational context provides learners fewer opportunities to foster intrinsic motivation? Could modelling some aspects of the Finnish educational system based less on competitiveness and excessive workload, support the design of attractive and engaging STEM learning environments while also maintaining the overall life satisfaction? Could, for example, the novel learning by moving approach be integrated into STEM studies so as to enhance the physical activity, learning, and motivation not only in Finland but also in Greece and elsewhere? Could the hybrid STEM learning environment also provide tools supporting teachers in scaffolding and motivating the students towards personalized and self-regulated learning or compensate the lack of laboratory equipment by the virtual laboratory simulations?

Despite some positive aspects of Finnish educational context, the concern of diminishing interests and competence in science and math amongst the Finnish learners indicates that there is a need for developing inspiring and effective STEM environments also in Finland. In fact, we argue that learning about the wishes expressed in differing educational context may support the design of learning environments, which consider contextual differences, on one hand, but also mutually enrich the local educational context based on the international exchange of experiences and future visions.

\section{LIMITATIONS}

The study is based on the analysis of focus group co-design sessions organized in two countries with a limited number of learner, teacher, director, parent, and STEM professional representatives. For this reason, we focused on wishes commonly shared by all stakeholders. Also, the differences identified between participants in Finland and in Greece are tentative. In the future analysis including also data from Belarus, Germany, and Spain, more attention can be paid to possible differences between stakeholder groups, countries, age groups and also on possible gender differences. While this analysis served as a base for identifying and formulating possible main themes based on participants' suggestions, in the future studies, we aim at refining the constructs and contents for the pedagogical framework and design principles for hybrid STEM learning environments. More attention can also be paid on STEM specific design principles. Further, quantitative analysis can be employed to seek the numeric support for this qualitative study.

\section{ACKNOWLEDGEMENTS}

This project has received funding from the European Union's Horizon 2020 research and innovation program, Science Technology Innovation Mathematics Engineering for the Young 2016-2019, under grant agreement No 709515. Any opinions, findings, and conclusions or recommendations expressed in this material reflect only the authors' views, and the Union is not liable for any use that may be made of the information contained therein. We are especially grateful to the stakeholders participating in the co-design both in Finland and Greece as well as to various researcher of this project who have contributed to this study.

\section{REFERENCES}

[1] European Union. EU STEM Coalition: STEM Skills for a Future-Proof Europe, April, 2016. 
[2] K.-H. Tseng, C.-C. Chang, S.-J. Lou and W.-P. Chen, "Attitudes towards science, technology, engineering and mathematics (STEM) in a project-based learning (PjBL) environment", International Journal of Technology Education, vol. 23, pp.87-102., 2013.

[3] P. Potvin, and A. Hasni, "Interest, motivation, and attitude towards science and technology at K12 levels: a systematic review of 12 years of educational research". Studies in Science Education, vol. 50, no. 1, pp. 85-129, 2014.

[4] A. Loukomies, D. Pnevmatikos, J. Lavonen, P. Kariotoglou, K, Juuti and A. Spyrtou, "Promoting students' interest and motivation towards science learning: The role of personal needs and motivation orientations". Journal of Research in Science Education, vol. 43, no. 5, pp. 25172539, 2013.

[5] J. Lavonen, R. Byman, A. Loukomies, V. Meisalo, C. Constantinou, T. Kyratsi... and I. Testa, "Students' Motivation on Learning Material Science Teaching Modules in Five Countries", in Contemporary science education research: Learning and assessment (G. Cakmakci and M.F. Taşar eds.), pp. 51-55., Ankara, Turkey: Pegem Akademi, 2010.

[6] J. Osborne, S. Simon, and S. Collins, "Attitudes towards science: A review of the literature and its implications", International journal of science education, vol. 25, no. 9, pp. 1049-1079, 2003.

[7] OECD, Education GPS, 2015. Retrieved from http://gpseducation.oecd.org/

[8] A. Spyrtou, J. Lavonen, A. Zoupidis, A. Loukomies, D. Pnevmatikos, K. Juuti and P. Kariotoglou, "Transferring a Teaching Learning Sequence between two different educational contexts: the case of Greece and Finland", International Journal of Science and Mathematics Education, pp. 1-21, 2016.

[9] T. Mäkelä, M. Kankaanranta, and C. Gallagher, "Involving students in the redesign of learning environments conducive to learning and wellbeing", in Proceedings of the 6th Architectural Research Symposium in Finland 2014: Designing and Planning the Built Environments for Human Well-Being, 2014, pp. 268-282, 2014.

[10] J. Lowyck and J. Pöysä, "Design of collaborative learning environments", Computers in human behavior, vol. 17, no. 5, pp. 507-516, 2001.

[11] M. Jiménez Iglesias, A. Nistor, À. Gras-Velázquez, G. Balta, M. Caeiro Rodríguez, M. Caine and A. Valero, "Multi-stakeholder partnerships in STEM education", Scientix observatory series, 2016.

[12] K. D. Könings, T. Seidel, J. Jeroen and G. van Merriënboer, G., "Participatory design of learning environments: integrating perspectives of students, teachers, and designers". Instructional Science, vol. 42, no. 1, 2014.

[13] A. Duarte, L. Veloso, J. Marques and J. Sebastião, "Site-specific focus groups: analysing learning spaces in situ", International Journal of Social Research Methodology, vol. 18, no. 4, pp. 381-398, 2015.

[14] A. Strauss and J. Corbin, Basics of Qualitative Research - Techniques and Procedures for Developing Grounded Theory, second edition, London, Sage Publications, 1998.

[15] G. O'Neill and T. McMahon, "Student-centred learning: What does it mean for students and lecturers?" in Emerging Issues in the Practice of University Learning and Teaching, (G. O'Neill, G. Moore and B. McMullin, eds.). Dublin: AISHE, 2005.

[16] W. Rubens, B. Emans, T. Leinonen, A. Gomez Skarmeta and R.-J. Simons, "Design of webbased collaborative learning environments. Translating the pedagogical learning principles to human computer interface," Computers \& Education, vol. 47, pp. 276-294, 2005.

[17] K. Hakkarainen and M. Sintonen, "The Interrogative Model of Inquiry and Computer-Supported Collaborative Learning," Science \& Education, vol, 11, no. 1, pp. 25-43, 2002.

[18] H. Muukkonen, K. Hakkarainen and M. Lakkala, "Collaborative Technology for Facilitating Progressive Inquiry: The Future Learning Environment Tools," In The proceedings of the CSCL '99 conference (C. Hoadley and J. Roschelle, eds.), December 1999, Palo Alto, pp. 406-415. Mahwah, NJ: Lawrence Erlbaum and Associates, 1999. 
[19] P.H.M. Cremers, A.E.J. Wals, R. Wesselink and M. Mulder, "Design principles for hybrid learning configurations at the interface between school and workplace," Learning Environment Research, vol.19, pp. 308-334, 2016.

[20] D. Kokotsaki, V. Menzies, and A. Wiggins,"Project-based learning: A review of the literature," Improving Schools, vol. 19, no. 3, pp. 267- 277, 2016.

[21] Finnish National Board of Education, National Core Curriculum for Basic Education 2014. Vammala: Vammalan Kirjapaino, 2016.

[22] T. Mäkelä, and S. Helfenstein, "Developing a conceptual framework for participatory design of psychosocial and physical learning environments," Learning Environments Research, vol. 19, no. 3, pp. 411-440, 2016.

[23] K. Dimitriadou, and A. Spyrtou, "In service views and practices for teaching and learning science in primary education", in Proceedings of the 9th National Conference Greek Pedagogy and Educational Research, 2014, vol. 1, Florina, Greece, 2014.

[24] P.A. Kirschner, J. Sweller and R.E. Clark, "Why minimal guidance during instruction does not work: an analysis of the failure of constructivist, discovery, problem-based, experiential, and inquiry-based teaching", Educational Psychologist, vol. 41, no. 2, pp. 75- 86, 2006.

[25] E. L. Deci, and R. M. Ryan, "Overview of self-determination theory: An organismic dialectical perspective". In Handbook of self-determination research (E. Deci and R.M. Ryan, eds.), pp. 333, The University of Rochester Press, 2002.

[26] R. M. Ryan, and E. L. Deci, "Self-determination theory and the facilitation of intrinsic motivation, social development, and well-being", American psychologist, vol. 55, no. 1, pp. 68-78, 2000. 